\title{
BMJ Open The effect of a school-based educational intervention on menstrual health: an intervention study among adolescent girls in Bangladesh
}

\author{
Syed Emdadul Haque, ${ }^{1,2}$ Mosiur Rahman, ${ }^{3}$ Kawashima Itsuko, ${ }^{4}$ \\ Mahmuda Mutahara, ${ }^{5}$ Kayako Sakisaka ${ }^{6}$
}

To cite: Haque SE,

Rahman M, Itsuko K, et al. The effect of a school-based educational intervention on menstrual health: an intervention study among adolescent girls in Bangladesh. BMJ Open 2014:4:e004607. doi:10.1136/bmjopen-2013004607

- Prepublication history for this paper is available online. To view these files please visit the journal online (http://dx.doi.org/10.1136/ bmjopen-2013-004607).

Received 3 December 2013 Revised 3 June 2014 Accepted 12 June 2014

CrossMark

For numbered affiliations see end of article.

Correspondence to Dr Syed Emdadul Haque; emdad91@gmail.com

\section{ABSTRACT}

Objectives: To assess the impact of a school-based menstrual education programme on: (1) menstrual knowledge, beliefs and practices, (2) menstrual disorders experienced, and (3) restrictions on menstruating adolescents.

Design: Intervention study.

Setting: Araihazar area, Bangladesh.

Participants: 416 adolescent female students aged $11-16$ years, in grade $6-8$, and living with their parents.

Interventions: A school-based health education study conducted from April 2012 to April 2013.

Primary and secondary outcome measures: We randomly selected 3 of 26 high schools in the study area. We delivered 6 months of educational intervention by trained (by an obstetrician and gynaecologist) research assistants (RAs) on menstrual hygiene among school girls. RAs read the questionnaire and participants answered. The changes in knowledge, beliefs and practices regarding menstruation, menstrual disorders experienced, and the restrictions and behaviours practiced by menstruating adolescents were compared between the baseline and the follow-up assessments.

Results: After health education, participants reported a significant improvement $(p<0.001)$ in 'high knowledge and beliefs' scores compared to baseline ( $51 \%$ vs $82.4 \%$ ). Significant improvement was also observed in overall good menstrual practices $(28.8 \%$ vs $88.9 \%$ ), including improvements in using sanitary pads $(22.4 \%$ change after the intervention), frequency of changing pads/cloths per day (68.8\%), drying the used absorbent $(77.6 \%)$, methods of disposing of the used absorbent $(25.5 \%)$, and cleaning of genitalia $(19.2 \%)$. During the follow-up, the participants reported significant improvements in the regularity of their menstrual cycle $(94.5 \%$ vs $99.5 \%)$ and fewer complications during menstruation $(78.6 \%$ vs $59.6 \%)$.

Conclusions: The programme produced significant changes in the knowledge, beliefs and practices of menstrual hygiene, complications from lack of hygiene, and the behaviour and restrictions of the menstruating adolescents. These results demonstrate the feasibility of implementing a health education programme for

\section{Strengths and limitations of this study}

- This is the first study to evaluate a menstrual education programme among adolescent school girls in Bangladesh.

- This study evaluated the menstrual knowledge, beliefs and practices of, and menstrual disorders experienced by, students in grade $6-8$ in Bangladesh.

- The educational programme resulted in significant improvements in knowledge $(51 \%$ to $82.4 \%$ ), beliefs and practices ( $28.8 \%$ to $88.9 \%$ ).

- Significant improvements were also observed in restrictions on visits to relatives and friends, and in school attendance during menstruation.

- The same educational programme should be implemented for all adolescent girls in Bangladesh.

adolescents on menstrual hygiene in secondary schools serving rural Bangladesh.

\section{INTRODUCTION}

Adolescence is a period of rapid transition from girlhood to womanhood. The onset of menstruation is one of the most important changes that occur for girls during the adolescent years. ${ }^{1}$ The first menstruation (menarche) occurs between the ages of 11 and $15 .^{23}$ Poor menstrual hygiene and inadequate self-care are major determinants of morbidity and other complications among this age group. Some of these problems include urinary tract infections, scabies in the vaginal area, abnormal abdominal pain, absence from school, and complications during pregnancy. ${ }^{4-7}$ In many areas of developing countries, a culture of silence surrounds the topic of menstruation and related issues. ${ }^{8} 9$ As a result, many young girls lack appropriate information on menstrual 
hygiene. Infections due to lack of hygiene during menstruation have been reported in many studies. ${ }^{10-15}$ They also revealed that most adolescent girls had incomplete and inaccurate information about menstrual physiology and hygiene. The menstrual information they did have was acquired primarily through mothers, television, friends, teachers and relatives. ${ }^{5} 1617$

Menstruation is still regarded as unclean or dirty in Bangladeshi society. ${ }^{4}$ Because of various myths, misconceptions and restrictions practiced during menstruation, adolescent girls in Bangladesh often develop negative attitudes towards this natural physiological phenomenon. The majority of girls lack scientific knowledge about menstruation and puberty. ${ }^{18}$ Adolescent girls in Bangladesh are often reluctant to discuss this topic with their parents and hesitant to seek help regarding their menstrual problems. Most girls are not informed about menarche or how to manage menstrual bleeding. ${ }^{18}$ Studies in rural Bangladesh and India found that $69.0 \%$ of adolescent girls were using old pieces of cloth or even no protection at all during menstruation. ${ }^{19} 20$ Therefore, the need to create awareness and increase access to sanitary facilities essential for menstrual hygiene is important for school-aged adolescents in Bangladesh.

Learning about menstrual hygiene is a vital part of health education for adolescent girls so that they can continue to work and maintain hygenic habits throughout their adult life. ${ }^{21}$ The ideal menstrual health education curriculum would encourage students to think about the relationships between knowledge, choice, behaviours and enhanced human health. It would also help to improve maternal health, which can have an impact on the millennium development goals (MDGs), for example MDG5. ${ }^{22}$ However, despite the need to achieve MDGs, to our knowledge no study has been conducted on an educational intervention on menstrual hygiene among school girls in Bangladesh. Therefore, the present study was designed to evaluate the effectiveness of a school-based menstrual education programme regarding: (1) menstrual knowledge, beliefs and practices, (2) menstrual disorders experienced, and (3) the restrictions practiced by 6-8 grade school girls in Bangladesh.

\section{METHODS}

Study design and participants

This intervention study was conducted in Araihazar Thana in the Narayanganj District in Bangladesh. Araihazar Thana is $25 \mathrm{~km}$ south-east of the capital, Dhaka. It has a total area of $183.35 \mathrm{~km}^{2}, 63080$ household units and a population of 331556 . Males constitute $51.7 \%$ of the population, and females $48.3 \%$. Araihazar has an average literacy rate of $53.0 \%$ ( $7+$ years of formal education), compared to the national average of $68.4 \% .^{23}$

Of 26 high schools (grade 6-10) in the study area, 2 were full government schools and 24 were semi- government schools. We selected one of the government schools and two of the 24 semi-government schools using a simple random sampling method (we drew numbers). We only selected three schools due to limited time and resources. These schools were well-established, older schools and conveniently located. One was a girls-only school and the other two were co-educational. The socio-economic, cultural, religious and geographical characteristics of the schools were very similar. The schools were more than $2 \mathrm{~km}$ apart. A total of 597 adolescent girl attended the three schools, 438 of whom were willing to join the study. Participants were selected using the following criteria: (1) they were in grades $6-8$, (2) were not critically ill, and (3) had achieved menarche. As 22 girls had not yet reached menarche, 416 participants were recruited (figure 1). Participants were between 11 and 16 years of age and were living with their parents.

\section{Data collection procedures}

Before conducting each interview, the principal investigator (SEH) visited all three schools and received permission to conduct the survey and to provide health education to the adolescent girls attending the school. After permission was received, we conducted a pilot survey of the questionnaire and revised it, as suggested, for the final survey. In accordance with the general guidelines required for a full study, we selected $10 \%$ of the sample $(n=42)$ for a pilot test in one of the schools in the study area. ${ }^{24}$ The questionnaire was drafted in English and then translated into Bangla, the national language of Bangladesh. Back-translation from Bangla to English was carried out as a validation exercise before and after the pre-test questionnaire was administered. We also modified the questionnaire based on the results of the pre-test exercise to make it easier to understand and to answer. The baseline survey was conducted in April 2012. Trained research assistants (RAs) read the questions out loud and the participants answered. A group of 12-15 students participated in each exercise led by one RA, and we requested them not to discuss the survey questions with their peers. After each session, we invited another group to participate in the survey. The room was provided by the school.

After completion of the baseline survey, we hired a supervisor, a local obstetrician/gynaecologist, and three RAs with good knowledge of the study's target population. Before the survey, we gave 4 days of training to the RAs and one female teacher (selected from the participating schools) on adolescent health education, focusing on menstrual hygiene and the importance of maintaining the confidentiality of the participants' information. The training was delivered using a field manual which we had developed in the Bangla language. Menstrual education focused on menstrual hygiene knowledge, beliefs and behaviours, menstrual disorders, and restrictions on menstruating adolescents. The educational materials were developed by an obstetrician/ 
Figure 1 Selection of the sample.

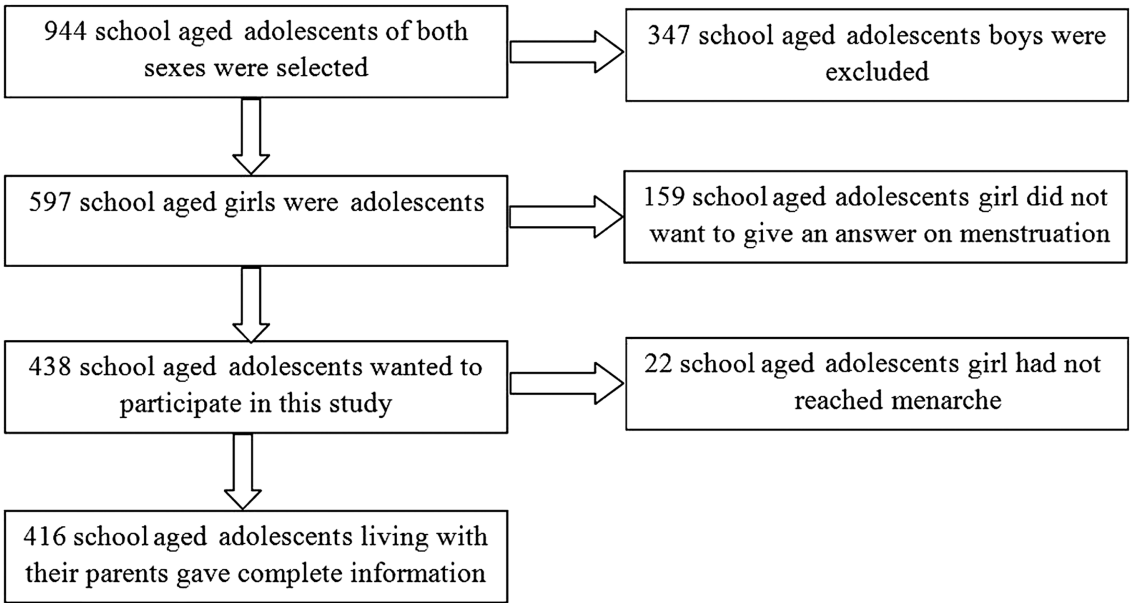

gynaecologist and were culturally acceptable to the girls. They received menstrual health education from the female RAs and in the same classroom where they were regularly taught. Males were not allowed entry to the room during health education. Twelve 45-min lessons were delivered by the RAs once every 15 days. The RAs also used clean cloths and pads for demonstration purposes, and showed the girls how to dry and store them. Female RAs were recruited for the study, so that adolescent girls would feel comfortable discussing these issues. Furthermore, 12 focus group discussions (FGDs) were conducted in the schools so that RAs and adolescent girls could become well acquainted with each other, as menstruation is a very sensitive topic in Bangladesh. In addition, FGDs were conducted in order to evaluate the effectiveness of the intervention using a qualitative approach. After 6 months of intervention, follow-up data were collected in the schools using the same questionnaire as at baseline regarding menstrual hygiene knowledge, beliefs and practices, types of complications, and restrictions on menstruating adolescents. RAs visited the homes of any students who were not available at school during the follow-up data collection. In students' homes, RAs provided the questionnaire to the students and spoke with them in a private room in keeping with the data collection method in the schools.

In addition to collecting other socio-economic data, we also asked the participants about the number of persons per sleeping room in their home; the type of floor in the house; the type of roof; the type of wall; the type of cooking fuel; the presence of household assets including an electricity supply, radio, TV, mobile phone, refrigerator, watch, bicycle, motorcycle, and source of drinking water; and type of sanitary facility.

This study protocol was reviewed and approved by the ethics committee of the Bangladesh Medical Research Council (BMRC). Prior to the baseline survey, participants were informed about the study, invited to participate, and told of their right to decline. Written consent was obtained from parents and verbal consent was obtained from the head teacher, class teacher and participants. In addition, we obtained written permission for this study from the local Education Officer under the Ministry of Education (MoE) in Bangladesh.

\section{Measures}

Intervention components

Knowledge and beliefs about menstruation

This section of the questionnaire consisted of 10 multiple choice questions to determine pupils' knowledge regarding: (1) normal monthly duration of menstruation, (2) poor menstrual hygiene predisposing to infection, (3) hygienic practices preventing menstrual pain, (4) menstrual blood being considered impure, (5) proper sanitary products, (6) cause of menstruation, (7) origin of menstrual blood, (8) age of normal cessation of menstruation, (9) hot or cold food affecting the menstrual cycle, and (10) menstruation as indicating fertility (fecundity).

The students' knowledge and beliefs were scored using a system adopted from previous studies. ${ }^{25-27}$ Each correct response was awarded 1 point, while incorrect or 'don't know' answers received no marks. This gave a total possible score of 10 points. Respondents who scored 0-3 points were adjudged to have poor knowledge, those with 4-7 points to have medium knowledge, and those with 8-10 points to have high knowledge. Cronbach's $\alpha$ was 0.73 for the knowledge and beliefs instrument.

\section{Practices related to menstrual hygiene}

This section of the questionnaire consisted of seven items assessing girls' menstrual hygiene practices: (1) of changing the absorbent each day, (3) drying of the used absorbent, (4) storing of washed clothes, (5) methods of disposal of the used absorbent, (6) cleaning of external genitalia, and (7) material used for cleaning of external genitalia. A score of 2 was given for good hygienic practices, a score of 1 was given for fair practices, and a score of 0 was given for poor practices. The maximum score was 14 points. Students who scored 0-4 the absorbent used during menstruation, (2) frequency 
points, 5-8 points and $9+$ points were judged to have poor, fair and good practices, respectively. Cronbach's $\alpha$ was 0.82 for the practice instrument.

\section{Menstrual disorders experienced and restrictions during menstruation}

Regarding menstrual disorders experienced by the adolescent, the following items were evaluated: (1) regularity of menstrual cycle, (2) types of complications experienced during menstruation, and (3) consultation with someone for menstrual-related complications. This section also contained items to assess girls' restrictions during menstruation: (1) visits to holy places, (2) visits to relatives, friends and neighbours, (3) participation in household activities, and (4) school attendance during menses. Dysmenorrhoea was considered as pain in the abdominal, groin or lumbar regions on the day before or on the first day of menstruation. ${ }^{28}$ We also assessed adolescent depression using the Children's Depression Inventory (CDI) ${ }^{29}$ The CDI evaluates feelings and ideas grouped into 27 items. Scores range from 0 to 54 . Cronbach's $\alpha$ was 0.73 for this section. We considered a cut-off score on the CDI of $\geq 20$ to indicate depressed mood. ${ }^{30} 31$

Stress was measured using the validated Perceived Stress Scale-10 (PSS) ${ }^{32}{ }^{33}$ PSS scores range from 0 to 40, with a high score representing high social stress. Cronbach's $\alpha$ was 0.75 . A score $\geq 20$ was considered to indicate high stress. ${ }^{31}$

\section{Statistical analysis}

Data were cross-checked for consistency before final data entry using Microsoft Excel. One person entered the data and then cross-checked it with the principal investigator of the study. Descriptive analyses were conducted to determine the socio-demographic characteristics of the respondents. The household wealth index was used as a proxy indicator for household wealth status. The wealth index was constructed from existing data on a household's ownership of 15 assets and house construction materials as reported by the participants. Each asset was assigned a weight (factor score) generated through principle components analysis, and the resulting asset scores were standardised to a standard normal distribution with a mean of 0 and an SD of 1 . Each household was then assigned a score for each asset, and the scores were summed by household. The sample was then divided into population tertiles: poor, middle and rich. We used McNemar's $c^{2}$ analyses as the same individuals are measured twice (before and after the survey) to evaluate the impact of an education programme on four recurrent themes of menstruation between baseline and follow-up: (1) knowledge and beliefs, (2) menstrual disorders experienced, (3) hygiene practices, and (4) menstruation behaviour and restrictions of the school-aged adolescent girls. All analyses were performed using the Statistical Package for the Social Sciences (SPSS) V.18 (SPSS, Chicago, Illinois, USA). In all analyses, the level of significance was set at $\mathrm{p}<0.05$ (two-tailed).

\section{RESULTS}

More than half of the respondents $(52.4 \%)$ were $11-$ 13 years old, $13.7 \%$ reported that their father had no education, and $11.8 \%$ reported that their mother had no education (table 1). Approximately $95 \%$ were Muslim and $41.8 \%$ reported there were six or more members in their household. Of 416 participants, 27.9\% were defined as being poor, $34.6 \%$ as being moderately well-off, and $37.5 \%$ as being rich. Regarding house type, $17.1 \%$ reported they lived in a pakka (a house made of bricks), $14.4 \%$ in a half-pakka (where only the floor is made of brick), and $68.5 \%$ in a kacha house (no bricks were used to build the house) (table 1).

In the pre-test stage, $77.4 \%, 68.3 \%$ and $67.1 \%$ of the girls said that they knew how long a normal menstrual cycle lasted (between 21 and 35 days), that poor menstrual hygiene can predispose to infection, and that hygienic practices during menstruation can prevent menstrual pain. At follow-up, adolescents had significantly

Table 1 Socio-demographic characteristics of the participants $(n=416)$

\begin{tabular}{|c|c|c|}
\hline Characteristic & Number (N) & Per cent $(\%)$ \\
\hline \multicolumn{3}{|l|}{ Age (years) } \\
\hline $11-12$ & 64 & 15.4 \\
\hline 13 & 154 & 37.0 \\
\hline $14+$ & 198 & 47.6 \\
\hline \multicolumn{3}{|l|}{ Religion } \\
\hline Muslim & 394 & 94.7 \\
\hline Non-Muslim & 22 & 5.3 \\
\hline \multicolumn{3}{|l|}{ Father's education } \\
\hline No education & 57 & 13.7 \\
\hline Incomplete primary & 176 & 42.3 \\
\hline Complete primary & 94 & 22.6 \\
\hline Secondary or higher & 89 & 21.4 \\
\hline \multicolumn{3}{|l|}{ Mother's education } \\
\hline No education & 49 & 11.8 \\
\hline Incomplete primary & 173 & 41.6 \\
\hline Complete primary & 119 & 28.6 \\
\hline Secondary or higher & 75 & 18.0 \\
\hline \multicolumn{3}{|l|}{ Household size } \\
\hline $2-4$ & 116 & 27.9 \\
\hline 5 & 126 & 30.3 \\
\hline $6+$ & 174 & 41.8 \\
\hline \multicolumn{3}{|l|}{ House type } \\
\hline Pakka & 71 & 17.1 \\
\hline Half-pakka & 60 & 14.4 \\
\hline Kacha & 285 & 68.5 \\
\hline \multicolumn{3}{|l|}{ Wealth index* } \\
\hline Poor & 116 & 27.9 \\
\hline Middle & 144 & 34.6 \\
\hline Rich & 156 & 37.5 \\
\hline
\end{tabular}

${ }^{*}$ Constructed from data on household assets, including ownership of durable goods (such as televisions and bicycles) and dwelling characteristics, such as source of drinking water, sanitation facilities, and type of construction. We used principal components analyses to assign individual household wealth scores.

Pakka means brick-built, half-pakka means only the floor is made of brick, and kacha means no brick was used to construct the house. 
Table 2 Impact of menstrual educational programme on menstruation knowledge and beliefs $(n=416)$

\begin{tabular}{|c|c|c|c|c|c|c|}
\hline \multirow[b]{2}{*}{ Characteristics } & \multicolumn{2}{|c|}{ Baseline } & \multicolumn{2}{|c|}{ Follow-up } & \multirow{2}{*}{$\begin{array}{l}\text { Percentage } \\
\text { change }\end{array}$} & \multirow[b]{2}{*}{ p Value } \\
\hline & $\overline{\mathbf{N}}$ & Per cent & $\overline{\mathbf{N}}$ & Per cent & & \\
\hline Duration of normal menstruation cycle & 322 & 77.4 & 389 & 93.5 & 16.1 & 0.002 \\
\hline Poor menstruation hygiene predisposes to infection & 284 & 68.3 & 398 & 95.7 & 27.4 & $<0.001$ \\
\hline Good hygiene can prevent menstrual pain & 279 & 67.1 & 391 & 94.0 & 26.9 & $<0.001$ \\
\hline Menstruation blood is impure & 279 & 67.1 & 399 & 95.9 & 28.8 & $<0.001$ \\
\hline $\begin{array}{l}\text { Proper sanitary products should be used for menstruation } \\
\text { protection }\end{array}$ & 241 & 57.9 & 339 & 81.5 & 23.6 & $<0.001$ \\
\hline Cause of menstruation & 334 & 80.3 & 353 & 84.8 & 4.5 & 0.886 \\
\hline Origin of menstrual blood & 41 & 9.9 & 55 & 13.2 & 3.3 & 0.687 \\
\hline Age of normal cessation of menstruation & 245 & 58.9 & 352 & 84.6 & 25.7 & $<0.001$ \\
\hline Influence of hot or cold food on menses & 273 & 65.6 & 358 & 86.1 & 20.5 & 0.001 \\
\hline As an indication of fertility (fecundity) & 179 & 43.0 & 190 & 45.7 & 2.7 & 0.556 \\
\hline \multicolumn{7}{|l|}{ Knowledge and beliefs grading } \\
\hline Poor (0-3) & 120 & 28.8 & 7 & 1.7 & -27.1 & $<0.001$ \\
\hline Medium (4-7) & 84 & 20.2 & 66 & 15.9 & -4.3 & \\
\hline High $(8-10)$ & 212 & 51.0 & 343 & 82.4 & 31.4 & \\
\hline
\end{tabular}

Bold typeface indicates significance level $<0.05$.

increased $(\mathrm{p}<0.001)$ their knowledge of these three items $(93.5 \%, 95.7 \%$ and $94 \%)$. At follow-up, adolescents also mentioned that they now knew that menstrual blood was not impure $(67.1 \%$ vs $95.9 \%)$ and that proper sanitary products should be used for menstrual protection $(57.9 \%$ vs $81.5 \%)$. There was no statistically significant difference between baseline and follow-up regarding respondents' knowledge of the cause of menstruation, origin of menstrual blood, or that menstruation indicated fertility. However, during the follow-up period, adolescents significantly increased their knowledge regarding age at normal cessation of menstruation and the fact that hot and cold foods do not influence the menstrual cycle. Overall, significant improvement $(\mathrm{p}<0.001)$ was observed regarding adolescents' self-reported knowledge and beliefs scores at follow-up compared with baseline $(51 \%$ vs $82.4 \%$; table 2 ).

Regarding the absorbent used during menstruation, at baseline over $16 \%$ of participants mentioned that they used sanitary pads during menstruation, increasing to over $39 \%$ after the education programme. The frequency of changing pads/cloths per day and drying the absorbent outside in sunlight was higher at follow-up compared with baseline. No significant differences were observed in the storing of washed clothes between baseline and follow-up. Disposal of the absorbent by burial/burning or putting in a dustbin was significantly higher at follow-up compared with baseline. The was a significant improvement at follow-up compared to baseline in cleaning the genitalia every time the toilet was used or during bathing (table 3). However, no significant differences were observed in the material used to clean external genitalia between baseline and follow-up. Regarding hygienic practices, more participants stated that they practised good hygiene $(88.9 \%$ vs $28.8 \%$ ) at follow-up compared to baseline.

At baseline, $94.5 \%$ and $78.6 \%$ of girls reported that they had regular menstrual cycles and had experienced complications during menstruation. At follow-up, there was a significant improvement in the regularity of the menstrual cycle $(99.5 \% ; \mathrm{p}=0.023)$ and fewer complications during menstruation (59.6\%; $\mathrm{p}=0.003)$. As regards physiological symptoms, significantly fewer adolescents reported excessive bleeding and greasy skin at follow-up compared with baseline. Regarding dysmenorrhoea, significantly fewer adolescents reported abdominal pain and nausea and/or vomiting at follow-up. Regard psychological symptoms, there were significant differences in the amount of discomfort, stress and depression between baseline and follow-up. At follow-up, respondents stated that they were significantly more likely to consult someone for menstrual-related complications than at baseline $(99.8 \%$ vs $90.8 \%$; table 4$)$. In the baseline survey, $45.4 \%$ reported that they did not visit relatives, friends or neighbours during menstruation and $7.7 \%$ reported that they did not attend school during menstruation (table 4). At follow-up, significant improvements were observed with regard to restrictions followed by the girls. However, there were no significant differences regarding restrictions on visits to holy places or doing household activities during menses.

\section{DISCUSSION}

To the best of our knowledge, this is the first study to evaluate the effect of a school-based educational intervention on the menstrual knowledge, beliefs and practices of adolescent girls in Bangladesh. The present study demonstrates that knowledge and beliefs regarding menstrual hygiene were low before implementation of the programme. After implementation, there was a significant increase in knowledge among the adolescents (51\% vs $82.4 \%)$. This finding agrees with the results of other studies in Saudi Arabia and Egypt. ${ }^{34} 35$ 
Table 3 Impact of menstrual educational programme on menstrual hygiene practices by adolescent girls $(n=416)$

\begin{tabular}{|c|c|c|c|c|c|c|}
\hline \multirow[b]{2}{*}{ Characteristics } & \multicolumn{2}{|c|}{ Baseline } & \multicolumn{2}{|c|}{ Follow-up } & \multirow{2}{*}{$\begin{array}{l}\text { Percentage } \\
\text { change }\end{array}$} & \multirow[b]{2}{*}{ p Value } \\
\hline & $\overline{\mathbf{N}}$ & Per cent & $\overline{\mathbf{N}}$ & Per cent & & \\
\hline Absorbent used during menstruation & & & & & & 0.003 \\
\hline Sanitary pad & 70 & 16.8 & 163 & 39.2 & 22.4 & \\
\hline New cloths & 207 & 49.8 & 209 & 50.2 & 0.4 & \\
\hline Old cloths/other & 139 & 33.4 & 44 & 10.6 & -22.8 & \\
\hline Frequency of changing pad/cloths per day & & & & & & $<0.001$ \\
\hline $4+$ times & 35 & 8.4 & 321 & 77.2 & 68.8 & \\
\hline 2-3 times & 322 & 77.4 & 93 & 22.4 & -55.0 & \\
\hline 1 time & 59 & 14.2 & 2 & 0.5 & -13.7 & \\
\hline Drying of used absorbent & & & & & & $<0.001$ \\
\hline Outside room in sunlight & 78 & 18.8 & 401 & 96.4 & 77.6 & \\
\hline Inside room with sunlight & 46 & 11.1 & 5 & 1.2 & -9.9 & \\
\hline Inside/outside room without sunlight & 292 & 70.1 & 10 & 2.4 & -67.7 & \\
\hline Storing of washed cloths & & & & & & 0.077 \\
\hline Clean and covered place ${ }^{*}$ & 159 & 38.2 & 170 & 40.8 & 2.6 & \\
\hline Clean and open space $\dagger$ & 104 & 25.0 & 85 & 20.4 & -4.6 & \\
\hline Unclean and open/covered place & 153 & 36.8 & 129 & 31.0 & -5.8 & \\
\hline Method of disposal & & & & & & 0.004 \\
\hline Buried/burned/dustbin & 235 & 56.5 & 341 & 82.0 & 25.5 & \\
\hline Latrine & 65 & 15.6 & 49 & 11.8 & -3.8 & \\
\hline Throw on road & 116 & 27.9 & 26 & 6.2 & -21.7 & \\
\hline Cleaning of genitalia & & & & & & 0.005 \\
\hline Every time use toilet & 65 & 15.6 & 145 & 34.8 & 19.2 & \\
\hline During bathing & 202 & 48.6 & 254 & 61.1 & 12.5 & \\
\hline Do not clean & 149 & 35.8 & 17 & 4.1 & -31.7 & \\
\hline Material used for cleaning of external genitalia & & & & & & 0.448 \\
\hline Water and antiseptic & 30 & 7.2 & 45 & 10.8 & 3.6 & \\
\hline Soap and water & 199 & 47.8 & 191 & 45.9 & -1.9 & \\
\hline Only water/not cleaning & 187 & 45.0 & 180 & 43.2 & -1.8 & \\
\hline Practice grading & & & & & & 0.012 \\
\hline Poor $(0-4)$ & 60 & 14.4 & 3 & 0.7 & -13.7 & \\
\hline Fair (5-8) & 236 & 56.8 & 43 & 10.3 & -46.5 & \\
\hline Good (9+) & 120 & 28.8 & 370 & 88.9 & 60.1 & \\
\hline
\end{tabular}

*Suitcase, box, and cupboard.

†Store room, anywhere in the room, under a cushion, under the bed, behind the door, in the washroom.

¥Gallery, under the kitchen roof, anywhere in the room, under a cushion, under the bed, behind the door, in the washroom.

Hygienic practices during menstruation are very important as poor hygiene affects health by increasing vulnerability to infections of the urinary tract and perineum, ${ }^{4}$ and the reproductive tract. ${ }^{36}$ In this study, only $22.4 \%$ of girls used pads even after the health intervention. The remainder used poor quality cloths dyed with toxic pigments, which might make them susceptible to uterine pain. The girls also dry the cloths inside the house, which also might have effects. Good hygiene, such as the use of sanitary pads and adequate washing of the genital area, is essential during menstruation. ${ }^{4-6}$ Girls of reproductive age need access to clean and soft absorbent sanitary products, which protects their health in the long run. In the present study, during the pre-intervention phase, only $28.8 \%$ of adolescents had good hygiene practices. In the post-intervention phase, there was a significant improvement in good menstrual practices $(60.1 \%)$. Various studies have shown that health education increases knowledge and positive attitudes towards puberty as a natural physiological phenomenon. ${ }^{37}$
Regarding menstrual disorders among adolescent girls, in the pre-intervention phase, $10.6 \%$ and $6.7 \%$ of the adolescents reported excessive bleeding and greasy skin, respectively. After implementation of the programme, there was a significant reduction in such disorders. Dysmenorrhoea is a very common problem among adolescent girls and affects their quality of life. In the pre-intervention phase, $61.5 \%$ and $4.6 \%$ of adolescents experienced abdominal pain, and nausea and vomiting, respectively, which findings are similar to the results of a study in Egypt. ${ }^{35}{ }^{38}$ Dysmenorrhoea (pain during menses) was reported by most students in this study, with $59.8 \%$ reporting severe pain followed by back ache and fatigue, corresponding to the findings of a study carried out among Malaysian school girls in 2009. ${ }^{39}$ The use of oral contraceptives and hot drinks, respectively, may suppress ovulation and help reduce menstrual fluid prostaglandin activity levels which are responsible for dysmenorrhoea. Moreover, regular exercise can induce amenorrhoea and may decrease dysmenorhoea. ${ }^{40}$ 
Table 4 Impact of menstrual educational programme on menstrual disorders, behaviours and restrictions ( $\mathrm{n}=416$ )

\begin{tabular}{|c|c|c|c|c|c|c|}
\hline \multirow[b]{2}{*}{ Characteristics } & \multicolumn{2}{|c|}{ Baseline } & \multicolumn{2}{|c|}{ Follow-up } & \multirow{2}{*}{$\begin{array}{l}\text { Percentage } \\
\text { change }\end{array}$} & \multirow[b]{2}{*}{ p Value } \\
\hline & $\overline{\mathbf{N}}$ & Per cent & $\overline{\mathbf{N}}$ & Per cent & & \\
\hline \multicolumn{7}{|l|}{ Menstrual disorders experienced } \\
\hline Regularity of menstruation & 393 & 94.5 & 414 & 99.5 & 5.0 & 0.023 \\
\hline Complications during menstruation & 327 & 78.6 & 248 & 59.6 & -19.0 & 0.002 \\
\hline \multicolumn{7}{|l|}{ Types of complications during menstruation } \\
\hline \multicolumn{7}{|l|}{ Physiological symptoms } \\
\hline Excessive bleeding & 44 & 10.6 & 13 & 3.1 & -7.5 & $<0.001$ \\
\hline Headache & 32 & 7.7 & 28 & 6.7 & -1.0 & 0.789 \\
\hline Increase appetite & 26 & 6.2 & 18 & 4.3 & -1.9 & 0.297 \\
\hline Greasy skin & 28 & 6.7 & 6 & 1.4 & -5.3 & 0.002 \\
\hline \multicolumn{7}{|l|}{ Dysmenorrhoea } \\
\hline Pain in abdominal/groin/lumbar region & 256 & 61.5 & 219 & 52.6 & -8.9 & 0.012 \\
\hline Psychological symptoms & 35 & 8.4 & 13 & 3.1 & -5.3 & 0.025 \\
\hline Discomfort & 22 & 5.3 & 3 & 0.7 & -4.6 & 0.032 \\
\hline High stress* & 16 & 3.8 & 6 & 1.4 & -2.4 & 0.052 \\
\hline Irritability & 18 & 4.3 & 3 & 0.7 & -3.6 & 0.044 \\
\hline \multicolumn{7}{|l|}{ Depressiont } \\
\hline $\begin{array}{l}\text { Consult with someone for menstruation-related } \\
\text { complications }\end{array}$ & 378 & 90.8 & 415 & 99.8 & 9.0 & 0.003 \\
\hline \multicolumn{7}{|l|}{ Behaviours and restrictions } \\
\hline Visit relatives, friends and neighbours during menses & & & & & & 0.002 \\
\hline No & 189 & 45.4 & 110 & 26.4 & -19.0 & \\
\hline Yes & 227 & 54.6 & 306 & 73.6 & 19.0 & \\
\hline Do household activities during menses & & & & & & 0.438 \\
\hline No & 94 & 22.6 & 85 & 20.4 & -2.2 & \\
\hline Yes & 322 & 77.4 & 331 & 79.6 & 2.2 & \\
\hline Attend school during menses & & & & & & 0.019 \\
\hline No & 32 & 7.7 & 11 & 2.6 & -5.1 & \\
\hline Yes & 384 & 92.3 & 405 & 97.4 & 5.1 & \\
\hline
\end{tabular}

Regarding psychological symptoms, discomfort and stress were also significantly reduced at follow-up. Also at follow-up, the girls were more likely to consult someone about menstrual-related complications than at baseline $(99.8 \%$ vs $90.8 \%)$.

This study also demonstrated that respondents reported significant improvements in the regularity of their menstrual cycles at follow-up, possibly because they had significantly improved their knowledge, beliefs and menstrual hygiene practices. Other studies also suggest clear links between poor menstrual hygiene and vaginal scabies, abnormal discharge, and urinary and reproductive tract infections. ${ }^{41}$ These infections can upset the balance of hormones and cause irregular bleeding. ${ }^{42}$ In addition, participants' discomfort and stress also decreased significantly after the health intervention. Previous studies have shown that when a woman is stressed, her adrenal glands secrete the hormone cortisol, which may disrupt normal hormone function and cause irregular bleeding. ${ }^{43}$

During the pre-intervention phase, $45.4 \%$ of the girls reported that they did not visit relatives, friends or neighbours during menstruation, and $7.7 \%$ reported that they did not attend school during menstruation.
Significant improvements were observed regarding these restrictions at follow-up. However, no significant differences were observed regarding restrictions on visits to holy places or doing household activities during menstruation. These findings demonstrate that socio-cultural beliefs and taboos regarding menstruation are still widespread. Restrictions on menstruating women were also described in an Indian study ${ }^{5}$ which reported that girls do not perform housework during menstruation.

This intervention study has several important findings and insights for adolescent girls. However, it also has some limitations. First, the findings in this study were based on self-reported outcomes and may therefore differ from actual behaviour. Adolescents may have overreported their use of good menstrual hygiene in order to satisfy the interviewer. However, all the participants joined the health education session regularly. Second, information about complications was obtained from participants and not from medical records due to time and budget constraints, and so bias may have affected the reliability of the data. However, our RAs were trained by physicians to collect such information in a reliable manner. Third, although adolescents who experienced pain in the abdominal, groin and lumbar regions on the 
day before or the first day of menstruation, were considered to have dysmenorrhoea in this study, we did not assess the degree of pain using a pain scale. In future, we will certainly consider doing this. Also, this study concluded that education on menstruation helps to make the menstrual cycle more regular. However, this may have been due to the fact that the girls matured during the study and their cycles naturally became more regular. A study with a control group of girls of a similar age would be helpful to settle this issue.

Finally, although all possible efforts were made to standardise the educational intervention, it is possible that environmental factors such as differences in the abilities of RAs and their ability to disseminate study messages affected the outcome of the study. Despite such limitations, the results of the study provide important findings for policy makers seeking to improve adolescent reproductive health in Bangladesh.

\section{CONCLUSIONS AND RECOMIMENDATION}

These results demonstrate the feasibility of implementing a health education programme on menstrual hygiene in secondary schools serving rural Bangladesh. The programme produced significant positive changes in knowledge, beliefs, menstrual hygiene practices, experience of disorders, and restrictions on menstruating adolescents. More intense or longer interventions may be needed to significantly improve good menstrual hygiene practice in this population. Taking into account the health implications and prevailing socio-cultural and economic factors, effective strategies should be implemented to persuade adolescent school girls to adopt healthy menstrual practices. A well-informed continuous, school education programme should be delivered to students. In addition, the findings emphasise that information on safe hygiene and sanitary practices should be included in the school curriculum, and that there should be better communication between female students and their teachers, and between daughters and mothers.

\author{
Author affiliations \\ ${ }^{1}$ UChicago Research Bangladesh, Dhaka, Bangladesh \\ ${ }^{2}$ United Nations University-International Institute for Global Health (UNU- \\ IIGH), Kuala Lumpur, Malaysia \\ ${ }^{3}$ International Health and Medicine, Division of Public Health, Graduate School \\ of Medicine, Tokyo Medical and Dental University, Tokyo, Japan \\ ${ }^{4}$ Honjo International Scholarship Foundation, Tokyo, Japan \\ ${ }^{5}$ Wageningen University, Wageningen, The Netherlands \\ ${ }^{6}$ Faculty of Policy Studies, Chuo University, Tokyo, Japan
}

Acknowledgements The authors would like to thank all participants, teachers and education officers who helped with this research. We also thank Dr Nowsheen Sharmin Purabi, Registrar in Obstetrics and Gynaecology at Anwer Khan Medical College, Dhaka, Bangladesh for her training of, and support for, the research assistants, which made this research possible.

Contributors SEH and KS develop the proposal and implemented the study. $\mathrm{KI}$ and $\mathrm{MM}$ were involved in the field study. MR and SEH carried out the analyses and wrote the manuscript. All authors checked and approved the final manuscript.
Funding This study was funded by the Honjo International Scholarship Foundation, Japan.

\section{Competing interests None.}

Patient consent Obtained.

Ethics approval The Bangladesh Medical Research Council approved this study.

Provenance and peer review Not commissioned; externally peer reviewed.

Data sharing statement No additional data are available.

Open Access This is an Open Access article distributed in accordance with the Creative Commons Attribution Non Commercial (CC BY-NC 3.0) license, which permits others to distribute, remix, adapt, build upon this work noncommercially, and license their derivative works on different terms, provided the original work is properly cited and the use is non-commercial. See: http:// creativecommons.org/licenses/by-nc/3.0/

\section{REFERENCES}

1. World Health Organization. Adolescent friendly health services. An agenda for change. Geneva: World Health Organization, 2002.

2. McPherson ME, Korfine L. Menstruation across time: menarche, menstrual attitudes, experiences and behaviors. Womens Health Issues 2004;14:193-200.

3. Aniebue UU, Aniebue PN, Nwankwo TO. The impact of pre-menarcheal training on menstrual practices and hygiene of Nigerian school girls. Pan Afr Med J 2009;2:9.

4. Rokeya A, Kabita Y. Menstrual hygiene: breaking the silence. Water Aid Bangladesh 2007:283-7.

5. Dasgupta A, Sarkar M. Menstrual hygiene: how hygienic is the adolescent girl? Indian J Comm Med 2008;33:77-80.

6. Lawan UM, Yusuf NW, Musa AB. Menstruation and Menstrual Hygiene amongst Adolescent school Girls in Kano, Northwestern Nigeria. Afr J Reprod Health 2010;14:201-7.

7. Ayalew T, Meseret Y, Yeshigeta G. Reproductive health knowledge and attitude among adolescents: a community based study in Jimma Town, Southwest Ethiopia. Ethiop J Health Dev 2008;22:243-51.

8. Suneela G, Nandini S, Ragini S. Socio-cultural aspects of menstruation in an urban slum in Delhi, India. Reprod Health Matters 2001;9:16-25.

9. Olayinka $\mathrm{OO}$, Akinyinka $\mathrm{OO}$. Unmet need for sexuality education among adolescent girls in Southwest Nigeria: a qualitative analysis. Afr J Reprod Health 2004;8:27-37.

10. Ahuja A, Tiwari S. Awareness about pubertal changes among adolescent girls. J Fam Welfare 1995;41:46-50.

11. Chaudhari $\mathrm{RH}$. Socio-economic demographic and reproductive health profile of adolescents in the SAARC countries. Paper presented at the South Asia Conference on Adolescents; 21-23 July 1998; New Delhi, India.

12. Khanna A, Goyal RS, Bhawsar R. Menstrual practices and reproductive problems: a study of adolescent girls in Rajasthan $\checkmark$ Health Manag 2005;7:91-7.

13. Mudey AB, Keshwani N, Mudey GA, et al. A cross-sectional study on the awareness regarding safe and hygienic practices amongst school going adolescent girls in the rural areas of Wardha district. Global J Health Sci 2010;2:225-31.

14. Bhatia JC, Cleland J. Self-reported symptoms of gynecological morbidity and their treatment in south India. Stud Fam Plann 1995;26:491-5.

15. Mehra S, ed., Adolescent girl: an Indian perspective. Saket, New Delhi: MAMTA Health Institute for Mother and Child, 1995:75-8.

16. Ghattargi $\mathrm{CH}$, Deo DS. Preparation and practices regarding menstruation: a comparative study in rural and urban adolescent girls. Indian J Comm Med 2005;30:10-14.

17. Singh AJ. The place of menstruation in the reproductive lives of women of rural north India. Indian J Comm Med 2006;31:10-14.

18. Kabir B, Barua MK, Ahmed M. Improving menstrual hygiene facilities in secondary schools: initiatives from BRAC-WASH Program. Dhaka, Bangladesh, 31 January-2 February 2012.

19. Ali A, Mahmud SN, Karim A, et al. Knowledge and practice of NFPE-AGG graduates regarding menstruation. Dhaka: Bangladesh Rural Advancement Committee, 1996.

20. Drakshayani Devi K, Venkata Ramaiah P. A study on menstrual hygiene among rural adolescent girls. Indian J Med Sci 1994;48:139-43. 
21. Narayan KA, Srinivasa DK, Pelto PJ, et al. Puberty rituals, reproductive knowledge and health of adolescent school girls in South India. AP Pop Jour 2001;16:225-38.

22. Ten VTA. Menstrual hygiene: a neglected condition for the achievement of several Millennium Development Goals. Zoetermeer: Europe External Policy Advisors (EEPA), 2007. http://www.wsscc. org/resources/resource-publications/menstrual-hygiene-neglectedcondition-achievement-several-mdgs (accessed 30 May 2014)

23. Bangladesh Bureau of Statistics (BBS). BBS Report 2007. Government of the People's Republic of Bangladesh, 2007. http:// www.bbs.gov.bd/Home.aspx (accessed 12 Jun 2013).

24. Hertzog MA. Considerations in determining sample size for pilot studies. Res Nurs Health 2008;31:180-91.

25. Lawan UM, Yusuf NW, Musa AB. Menstruation and menstrual hygiene amongst adolescent school girls in Kano, Northwestern Nigeria. Afr J Reprod Health 2010;14:201-7.

26. Anju A, Patil R. Menstrual hygiene and practices of rural adolescent girls of Raichur. Int J Biol Med Res 2013;4:3014-17.

27. El-Gilany AH, Badawi K, El-Fedawy S. Menstrual hygiene among adolescent school girls in Mansoura, Egypt. Reprod Health Matters 2005;13:147-52.

28. Liu H, Yang F, Li Z, et al. Passive smoking, Cyp1A1 gene polymorphism and dysmenorrhea. Reprod Toxicol 2007;24: 114-19.

29. Kovacs M. The Children's Depression Inventory. Psychopharmacol Bull 1985;21:995-8.

30. Kovacs M. Children's Depression Inventory. North Tonawanda, NY: Multi-Health Systems, Inc, 1992

31. Yaacob SN, Mansor RJ, Ikechukwu AT. Loneliness, stress, self-esteem and depression among Malaysian adolescents. Jurnal Kemanusiaan Bil.14, Dis 2009.

32. Cohen S, Karmarck T, Mermelstein R. A global measure of perceived stress. J Health Soc Behav 1983;24:385-96.
33. Chakraborti A, Ray P, Sanyal D, et al. Assessing perceived stress in medical personnel: in search of an appropriate scale for the Bengali population. Indian J Psychol Med 2013;35:29.

34. Ayafi SA. Factors associated with health behavior regarding menstruation among Saudi intermediate school girls in Riyadh city [Master thesis]. Nursing College, King Saud University, 1999.

35. Hassanen $\mathrm{H}$, Tosson M, El-Elkareem EA. Effect of health education and training program for secondary school students on menstruation at Assiut Governorate. Bull High Inst Public Health 2004:34:575-94.

36. Sumpter $\mathrm{C}$, Torondel B. A systematic review of the health and social effects of menstrual hygiene management. PLOS ONE 2013;8: e62004.

37. Afzali M, Allameh R. Study of educational needs of 12-14 years old girls about adolescent health and determines appropriate and effective strategies for adolescent health education. Koomesh 2000;1:39-47.

38. Eswi A, Helal H, Elarousy W. Menstrual attitude and knowledge among Egyptian female adolescents. J Am Sci 2012;8:555-65.

39. Lee K, Chen Y, Lee K, et al. Menstruation among adolescent girls in Malaysia: a cross-sectional school survey. Singapore Med $J$ 2006;47:869-74.

40. Warren MP, Rebecca JL. What is the effect of exercise on primary dysmenorrheal? Products and prostaglandins as a root of menstruation. Br J Sports Med 1999;33:227.

41. Water Aid, Nepal. Menstrual hygiene in South Asia: a neglected issue for WASH (water, sanitation, and hygiene) programs. Pokhara, Nepal: WaterAid, 2008. http://www.wateraid.org/ /media/Publications/ menstrual-hygiene-south-asia.pdf (accessed 25 May 2014).

42. Hormone fact sheet. Health and Wellness Institute, Mountlake Terrace, WA 98043. 2013. http://hwifc.com/wp-content/uploads/ 2013/02/Detoxification_Fact_Sheet.pdf (accessed 25 May 2014).

43. Markovic N, Markovic O. What every woman should know about cervical cancer. Springer, 2008. 